University of Nebraska - Lincoln

DigitalCommons@University of Nebraska - Lincoln

Faculty Publications, Department of Psychology

Psychology, Department of

January 1978

\title{
Menstrual Cycle as Focus of Study and Self-Reports of Moods and Behaviors
}

Paula Englander-Golden
University of Oklahoma

Mary R. Whitmore

University of Oklahoma

Richard A. Dienstbier

University of Nebraska-Lincoln, rdienstbier2@unl.edu

Follow this and additional works at: https://digitalcommons.unl.edu/psychfacpub

Part of the Psychiatry and Psychology Commons

Englander-Golden, Paula ; Whitmore, Mary R.; and Dienstbier, Richard A., "Menstrual Cycle as Focus of Study and Self-Reports of Moods and Behaviors" (1978). Faculty Publications, Department of Psychology. 109.

https://digitalcommons.unl.edu/psychfacpub/109

This Article is brought to you for free and open access by the Psychology, Department of at DigitalCommons@University of Nebraska - Lincoln. It has been accepted for inclusion in Faculty Publications, Department of Psychology by an authorized administrator of DigitalCommons@University of Nebraska - Lincoln. 


\title{
Menstrual Cycle as Focus of Study and Self-Reports of Moods and Behaviors
}

\author{
Paula Englander-Golden \\ University of Oklahoma \\ Mary R. Whitmore \\ University of Oklahoma \\ Richard A. Dienstbier \\ University of Nebraska-Lincoln
}

Retrospective questionnaires show cyclical variations in moods and behaviors across the menstrual cycle. However, results obtained from daily mood questionnaires are inconsistent. In the present study, which ran for 11 weeks, self-report measures of menstrual symptomatology, using the 8-factor Moos (1968, 1969 a, c) Menstrual Distress Questionnaire (MDQ), were investigated. The MDQ was administered under conditions that made the menstrual cycle a salient (retrospective questionnaire) or not a salient (daily questionnaire) part of the study. The study included women who were taking and not taking oral contraceptives. A $2 \times$ 3 analysis of variance (with the two groups of women and three menstrual cycle phases as independent variables) yielded broad cyclical variations only in the menstrual cycle salient condition. When the menstrual cycle was not a salient part of the study, only the pain factor reached significant cyclical variation $(\mathrm{p}<.01)$. A $2 \times 3$ analysis of variance (with the two types of questionnaires and three menstrual cycle phases as independent variables) indicated that for women not taking oral contraceptives the two questionnaires differed on pain $(\mathrm{p}<.01)$, concentration $(\mathrm{p}<.01)$, autonomic reaction $(\mathrm{p}<.05)$, and water retention $(\mathrm{p}<.01)$. Phase effects were significant on all factors, with largest cyclical variations in the menstrual cycle salient condition. A similar analysis for women taking oral contraceptives yielded fewer significance differences. These results suggest that questionnaires that make the menstrual cycle a salient part of the study may exaggerate possible cyclical variations in moods and behaviors.

The authors are grateful to Dawn Christie Burns and Ross Hodges for their help in data reduction.

Requests for reprints should be addressed to Paula Englander-Golden, Human Relations Program, 601 Elm Street, Room 730, University of Oklahoma, Norman, Oklahoma 73019. 
$\mathrm{T}$ he expression "premenstrual syndrome" is a poorly defined catchall term that refers to moods and behaviors reported to recur as a function of the menstrual cycle. Over 150 different and sometimes contradictory symptoms have been associated with the menstrual cycle and reported to affect between $25 \%$ and $100 \%$ of women (Moos, 1968, 1969a). In a review of the premenstrual syndrome, Parlee (1973) pointed out that retrospective questionnaires yielded broad cyclical variations in moods, whereas results from daily questionnaires were inconclusive. Parlee concluded that as a scientific hypothesis the premenstrual syndrome has little more than face validity. Yet recent research has demonstrated differential performance for women on intellectual tasks across the menstrual cycle (Englander-Golden, Willis, \& Dienstbier, 1976). The above authors also reported significant differences in perception of interpersonal pressure as a function of the menstrual cycle (Englander-Golden et al., 1977).

In an attempt to identify and measure some of the cyclical variables reportedly associated with the menstrual cycle, Moos (1968, 1969a,b,c) developed the Menstrual Distress Questionnaire (MDQ). This questionnaire is composed of seven factors that Moos found to be stable and recurrent (pain, concentration, behavioral change, autonomic imbalance, water retention, negative affect, arousal), as well as a control factor composed of menopausal symptomatology. The latter factor serves as a lie scale. Although all eight factors appeared in each menstrual cycle phase (i.e., premenstrual, menstrual, and midcycle), the arousal and control factors did not show cyclical changes related to the menstrual cycle. Women who were not taking oral contraceptives differed significantly from those who were taking such $\mathrm{pHs}$ on factors of pain, concentration, negative affect, water retention, and behavioral change. Differences between the two groups were found only on reported symptoms for premenstrual and menstruating phases, with the nonpill group reporting more severe symptomatology. No differences were found on reported symptomatology for the midcycle phase.

Although Moos' MDQ has been used by other researchers (Silbergeld, Brast, \& Noble, 1971; Sommer, 1972; Gough, 1975; Rodin, 1976), a major substantive issue remains unsolved. The eight factors on the MDQ were established on the basis of retrospective self-reports by 839 women, whereas the stability of the factors over time was established on the basis of 15 women taken from the 
larger group of 839 . The 15 women were selected on the basis of their previous retrospective responses to the MDQ. Seven had complained of high premenstrual tension and 8 had complained of low premenstrual tension. These women rated a partial list of symptoms from the MDQ at different parts of the two consecutive menstrual cycles by responding how they felt "today" (Moos, 1969c). No comparison was made between a retrospective MDQ and an actual MDQ based on averaged' 'today" scores obtained on the appropriate days of the menstrual cycle for the larger sample of women. Thus it is possible that the factors obtained by Moos may be due to cultural expectations, which may exaggerate cyclical variations when women are aware that the menstrual cycle is being studied, and their stability may be due to the special selection of the small sample.

The present study was designed to investigate the possibility that responses to mood questionnaires by women who are aware that effects due to the menstrual cycle are being investigated may differ from responses given under conditions that do not make the menstrual cycle a salient part of the study. It was proposed to replicate Moos' results on the retrospective MDQ, which makes explicit that effects due to the menstrual cycle are being looked at, and to see whether a daily MDQ, covering the same menstrual cycle but obtained under the guise of a study in biological rhythms, would also yield similar cyclical variations. If the daily MDQ did not show such variations, it was hypothesized that a direct comparison of the two types of MDQs would show that they differed significantly on different factors. Since the two MDQs differed only on the dimension of awareness that the menstrual cycle was a part of the study, one might conclude that questionnaires which make women aware that their menstrual cycle is a part of the study maximize or exaggerate possible cyclical variations in moods and behaviors.

\section{METHODS}

\section{Subjects}

Subjects were undergraduate advanced zoology students who volunteered to participate in research for additional credit. A total of 91 students were in the lass, of which 70 were females; 60 females participated in the study. Of these, 24 were taking oral contraceptives. The final sample on which data analysis was based was restricted to 26 nonpill females and 20 pill females. The rationale for ubject selection is detailed in the Results section.

\section{Procedure}

The cover story that was used in the classroom to explain the rationale for the study emphasized that this was a study of biological rhythms that may be 
common to both males and females. Women were asked to make a note of onset and end of menstruation during the study, so that such effects could be "factored out." This statement was strictly for cover purposes since in reality these were precisely the effects under study. All subjects were asked to indicate any hormonal medication they might be taking during the study. This included information about oral contraceptives.

The study was conducted for 11 weeks. Students were asked to fill out daily questionnaires (Le., Moos' MDQ) in the evening in terms of "how you felt this day." The eight factors on the MDQ were pain, concentration, behavioral change, autonomic reaction, water retention, negative affect, arousal, and control. The items comprising these factors were rated from "not at all" to "very" on a 6point scale.

\section{The Actual $M D Q$}

Scores for the actual MDQ were obtained by averaging over the appropriate daily MDQs that defined the different phases of the menstrual cycle. The midcycle phase was defined as days $13,12,11,10,9,8$, and 7 prior to menstruation onset. Premenstrual phase was defined as days 5, 4, 3,2, and 1 prior to menstruation onset. Menstruating phase was defined as the first 5 menstruating days. $^{3}$

Two different actual MDQs were computed for each subject. One actual MDQ represented only the last cycle (actual last MDQ). The other actual MDQ represented an average over as many cycles as a subject had during the study (actual composite MDQ).

\section{The Remembered $M D Q$}

At the end of the study, subjects were reminded that in order to analyze the data for biological rhythms common to both males and females, one

\footnotetext{
The rationale for defining days 13 through 7 prior to the onset of menstruation as midcycle was based on the following considerations. Estrogens rise rapidly and reach a peak just before ovulation. However, within hours after the beginning of the LH surge, and before the rupture of the follicle, there is a precipitous drop in plasma estrogen. Estrogen begins to rise again during day 13 prior to the onset of menstruation (Williams, 1974). In some women the preovulatory drop in estrogen may be associated with high levels of MAO (Klaiber, 1976). Unless pregnancy intervenes, the levels of estrogen and progesterone begin to drop 7-8 days after ovulation (Williams, 1974). Since the LH peak occurs at day 15 prior to onset of menstruation and rupture of the follicle occurs 16-24 hours after the beginning of the LH surge (Williams, 1974), it was assumed that day 13 would be postovulatory for most women. Day 7 prior to onset of menstruation was included because levels of estrogen and progesterone appear to be still relatively high (Williams, 1974). Estrogen and progesterone are low in the premenstrual and menstruating phases (as defined in this study) for women not taking oral contraceptives (Williams, 1974).
} 
has to eliminate or "factor out" effects due to menstruation. Female students were therefore asked to fill out the same questionnaire that they had been filling out daily, in terms of how they remembered their most recent menstrual cycle. They were asked to fill out the questionnaire in terms of "how you felt in the most recent premenstrual, menstruating, and midcycle phases of your menstrual cycle." These phases were defined for the subjects as 5 days prior to the most recent menstruation, the days of most recent flow, and days 13 through 7 prior to onset of most recent flow.

At the end of the study a postexperimental questionnaire was administered to determine any suspicions subjects might have had during the study, and students were fully debriefed.

\section{RESULTS}

Data analysis was restricted to 26 nonpill females and 20 pill females. Although 36 nonpill females and 24 pill females participated in the study, some subjects were dropped for several reasons, including very irregular or absent menstrual cycles, and the use of insulin or diet control medication. The analysis was restricted to data from those subjects who had at least one cycle during the 11 weeks, namely, more or less regularly menstruating women.

A $2 \times 3$ analysis of variance for repeated measures (with pill versus nonpill and premenstrual, menstrual, and midcycle phases of the menstrual cycle as the two independent variables) was performed, on the remembered MDQ (Edwards, 1950).

Table I shows the means obtained by 26 nonpill women and 20 pill women on the eight factors of the remembered MDQ across the different phases of the menstrual cycle. $F$ values for main effects due to the nonpill pill variable (C), main effects due to menstrual phase $(\mathrm{P})$, and interaction effects $(\mathrm{C} \times \mathrm{P})$ are also indicated.

Examination of Table I shows significant main effects due to menstrual phase $(p<.01)$ on factors of pain, behavioral change, autonomic reaction, water retention, negative affect, and arousal. The concentration factor did not reach significance at the .05 level. There were no main effects due to the pill-nonpill variable. Interaction effects on factors of pain, concentration, and control were significant $(p<.05)$, and the interaction effect on negative affect barely missed the commonly accepted significance level, with $p<.059$.

The significant main effects due to menstrual phase replicated results reported by Moos with the exception of the arousal factor, on which Moos did not find such an effect, and the concentration factor, which in the present data did not reach significance at the .05 level. 
Table I. Means on Remembered MDQ by Condition and $F$ Values for Women Not Taking and Women Taking Oral Contraceptives

\begin{tabular}{|c|c|c|c|c|}
\hline MDQ factors & $\begin{array}{l}\text { Menstrual } \\
\text { phase }^{a}\end{array}$ & Nonpill (26) & Pill (20) & $F$ Values $b$ \\
\hline Pain & $\begin{array}{l}1 \\
2 \\
3\end{array}$ & $\begin{array}{l}1.85 \\
2.34 \\
1.40\end{array}$ & $\begin{array}{l}2.07 \\
1.96 \\
1.52\end{array}$ & $\begin{array}{l}\text { C: } .00 \\
\text { P: } 16.66^{c} \\
\text { C } \times \text { P: } 3.38^{d}\end{array}$ \\
\hline Concentration & $\begin{array}{l}1 \\
2 \\
3\end{array}$ & $\begin{array}{l}1.30 \\
1.54 \\
1.30\end{array}$ & $\begin{array}{l}1.36 \\
1.29 \\
1.29\end{array}$ & $\begin{array}{l}\text { C: } .28 \\
\text { P: } 2.47 e \\
\text { C } \times \text { P: } 4.46^{d}\end{array}$ \\
\hline Behavioral change & $\begin{array}{l}1 \\
2 \\
3\end{array}$ & $\begin{array}{l}1.73 \\
2.12 \\
1.40\end{array}$ & $\begin{array}{l}1.80 \\
1.88 \\
1.62\end{array}$ & $\begin{array}{l}\text { C: } .01 \\
\text { P: } 7.82 c \\
\text { C } \times \text { P: } 1.84\end{array}$ \\
\hline $\begin{array}{l}\text { Autonomic } \\
\text { reaction }\end{array}$ & $\begin{array}{l}1 \\
2 \\
3\end{array}$ & $\begin{array}{l}1.32 \\
1.58 \\
1.09\end{array}$ & $\begin{array}{l}1.17 \\
1.21 \\
1.08\end{array}$ & $\begin{array}{l}\text { C: } 2.52 \\
P: 5.86^{c} \\
C \times P: 2.03\end{array}$ \\
\hline $\begin{array}{l}\text { Water } \\
\text { retention }\end{array}$ & $\begin{array}{l}1 \\
2 \\
3\end{array}$ & $\begin{array}{l}2.18 \\
2.50 \\
1.53\end{array}$ & $\begin{array}{l}2.18 \\
1.99 \\
1.50\end{array}$ & $\begin{array}{l}\text { C: } .80 \\
\text { P: } 17.86^{c} \\
\text { C } \times \text { P: } 2.23\end{array}$ \\
\hline $\begin{array}{c}\text { Negative } \\
\text { affect }\end{array}$ & $\begin{array}{l}1 \\
2 \\
3\end{array}$ & $\begin{array}{l}1.90 \\
2.23 \\
1.45\end{array}$ & $\begin{array}{l}2.09 \\
1.94 \\
1.73\end{array}$ & $\begin{array}{l}\text { C: } .14 \\
\text { P: } 8.83^{c} \\
\text { C } \times \text { P: } 2.93^{e}\end{array}$ \\
\hline Arousal & $\begin{array}{l}1 \\
2 \\
3\end{array}$ & $\begin{array}{l}2.98 \\
2.97 \\
3.66\end{array}$ & $\begin{array}{l}3.10 \\
3.19 \\
3.56\end{array}$ & $\begin{array}{l}\text { C: } .07 \\
\text { P: } 10.49 c \\
\text { C } \times \text { P: } .70\end{array}$ \\
\hline Control & $\begin{array}{l}1 \\
2 \\
3\end{array}$ & $\begin{array}{l}1.15 \\
1.25 \\
1.10\end{array}$ & $\begin{array}{l}1.12 \\
1.12 \\
1.20\end{array}$ & $\begin{array}{l}\text { C: } .06 \\
\text { P: } .75 \\
\text { C } \times \text { P: } 4.42 d\end{array}$ \\
\hline
\end{tabular}

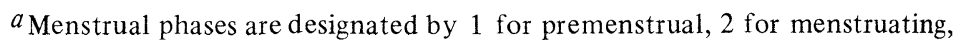
and 3 for midcycle.

$b_{F}$ tests for type of women's group $\mathrm{C}$ have 1 and 44 degrees of freedom; those for phase $\mathrm{P}$ and interaction $\mathrm{C} \times \mathrm{P}$ have 2 and 88 degrees of freedom.

$c^{c}$ Significant at $p<.01$.

$d_{\text {Significant at } p<.05 \text {. }}$.

$e$ Significant at $p<.10$.

As stated previously, Moos reported significant differences between non pill and pill women only premenstrually or menstrually on factors of pain, concentration, negative affect, water retention, and behavioral change. To replicate these results, the present results should have shown significant interaction effects on the above factors, with no differences between the two groups of women at midcycle and lower scores for the pill women compared to nonpill women in the other two phases. However, the only factors that satisfied part of these requirements were those of pain and concentration. The significant interaction effect found on the control factor was not predicted. 
A $3 \times 2$ factorial analysis of variance was also performed on the actual last MDQ. The two independent variables were nonpill versus pill and the three phases of the menstrual cycle. The dependent variable consisted of scores on the last actual MDQ. Table II summarizes these results in the same format as Table I.

Examination of Table II shows that only the pain factor replicated Moos' results inasmuch as it showed a significant main effect due to menstrual cycle $(p<.01)$. However, the interaction effect $(\mathrm{C} \times \mathrm{P})$ did not reach the usually accepted level of significance $(p<.05)$.

A similar analysis for the actual composite MDQ was performed. On this type of MDQ the scores were averaged over the appropriate phases of

Table II. Means on Actual Last MDQ by Condition and $F$ Values for Women Not Taking and Women Taking Oral Contraceptives

\begin{tabular}{|c|c|c|c|c|}
\hline MDQ factors & $\begin{array}{l}\text { Menstrual } \\
\text { phase }^{a}\end{array}$ & Nonpill (26) & Pill (20) & $F$ Values $b$ \\
\hline Pain & $\begin{array}{l}1 \\
2 \\
3\end{array}$ & $\begin{array}{l}1.49 \\
1.89 \\
1.58\end{array}$ & $\begin{array}{l}1.48 \\
1.66 \\
1.40\end{array}$ & $\begin{array}{l}\text { C: } .95 \\
\text { P: } 18.80^{c} \\
\text { C } \times \text { P: } 2.4 d\end{array}$ \\
\hline Concentration & $\begin{array}{l}1 \\
2 \\
3\end{array}$ & $\begin{array}{l}1.65 \\
1.59 \\
1.61\end{array}$ & $\begin{array}{l}1.49 \\
1.40 \\
1.53\end{array}$ & $\begin{array}{l}\text { C: } 1.25 \\
\text { P: } 1.40 \\
\text { C } \times \text { P: } .66\end{array}$ \\
\hline $\begin{array}{l}\text { Behavioral } \\
\text { change }\end{array}$ & $\begin{array}{l}1 \\
2 \\
3\end{array}$ & $\begin{array}{l}1.83 \\
1.93 \\
1.81\end{array}$ & $\begin{array}{l}1.81 \\
1.78 \\
1.72\end{array}$ & $\begin{array}{l}\text { C: } .33 \\
\text { P: } .92 \\
\text { C } \times \text { P: .45 }\end{array}$ \\
\hline $\begin{array}{l}\text { Autonomic } \\
\text { reaction }\end{array}$ & $\begin{array}{l}1 \\
2 \\
3\end{array}$ & $\begin{array}{l}1.16 \\
1.25 \\
1.19\end{array}$ & $\begin{array}{l}1.08 \\
1.06 \\
1.09\end{array}$ & $\begin{array}{l}\text { C: } 2.79 \\
\text { P: } .51 \\
\text { C } \times \text { P: } 1.31\end{array}$ \\
\hline $\begin{array}{l}\text { Water } \\
\text { retention }\end{array}$ & $\begin{array}{l}1 \\
2 \\
3\end{array}$ & $\begin{array}{l}1.52 \\
1.69 \\
1.57\end{array}$ & $\begin{array}{l}1.47 \\
1.49 \\
1.39\end{array}$ & $\begin{array}{l}\text { C: } 1.62 \\
\text { P: } 2.25 \\
\text { C } \times \text { P: } 1.03\end{array}$ \\
\hline $\begin{array}{c}\text { Negative } \\
\text { affect }\end{array}$ & $\begin{array}{l}1 \\
2 \\
3\end{array}$ & $\begin{array}{l}1.81 \\
1.77 \\
1.83\end{array}$ & $\begin{array}{l}1.78 \\
1.62 \\
1.84\end{array}$ & $\begin{array}{l}\text { C: } .16 \\
\text { P: } 2.52 d \\
\text { C } \times \text { P: } .85\end{array}$ \\
\hline Arousal & $\begin{array}{l}1 \\
2 \\
3\end{array}$ & $\begin{array}{l}3.42 \\
3.26 \\
3.30\end{array}$ & $\begin{array}{l}3.13 \\
3.31 \\
3.23\end{array}$ & $\begin{array}{l}\text { C: } .15 \\
\text { P: .04 } \\
\text { C } \times \text { P: } 1.72\end{array}$ \\
\hline Control & $\begin{array}{l}1 \\
2 \\
3\end{array}$ & $\begin{array}{l}1.22 \\
1.24 \\
1.31\end{array}$ & $\begin{array}{l}1.13 \\
1.12 \\
1.13\end{array}$ & $\begin{array}{l}\text { C: } 1.80 \\
\text { P: } 1.59 \\
\text { C } \times \text { P: } 1.39\end{array}$ \\
\hline
\end{tabular}

${ }^{a}$ Menstrual phases are designated by 1 for premenstrual, 2 for menstruating, and 3 for midcycle.

$b_{F}$ tests for type of women's group $\mathrm{C}$ have 1 and 44 degrees of freedom; those for phase $\mathrm{P}$ and interaction $\mathrm{C} \times \mathrm{P}$ have 2 and 88 degrees of freedom.

$c_{\text {Significant at } p<.01 \text {. }}$

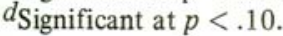


Table III. Means on Remembered and Actual Last Cycle MDQs by Condition and $F$ Values for Women Not Taking Oral Contraceptives

\begin{tabular}{lcccl}
\hline MDQ factors & $\begin{array}{c}\text { Menstrual } \\
\text { phase }^{a}\end{array}$ & Remembered (26) & Actual (26) & \multicolumn{1}{c}{$F$ Values $b$} \\
\hline \multirow{2}{*}{ Pain } & 1 & 1.85 & 1.49 & T: $6.27^{c}$ \\
& 2 & 2.34 & 1.89 & P: $19.14^{d}$ \\
Concentration & 3 & 1.40 & 1.58 & T $\times$ P: $6.19^{d}$ \\
& 1 & 1.30 & 1.65 & T: $13.45^{d}$ \\
Behavioral & 2 & 1.54 & 1.59 & P: 2.05 \\
change & 3 & 1.30 & 1.61 & T $\times$ P: $6.33^{d}$ \\
& 1 & 1.72 & 1.83 & T: 1.76 \\
Autonomic & 3 & 2.12 & 1.93 & P: $7.71^{d}$ \\
reaction & 1 & 1.41 & 1.81 & T $\times$ P: $4.12^{c}$ \\
& 2 & 1.32 & 1.16 & T: $4.73 c$ \\
Water & 3 & 1.58 & 1.25 & P: $6.17 d$ \\
retention & 1 & 1.09 & 1.19 & T $\times$ P: $4.36^{c}$ \\
& 2 & 2.18 & 1.52 & T: $22.50^{d}$ \\
Negative & 3 & 2.50 & 1.69 & P: $12.67 d$ \\
affect & 1 & 1.53 & 1.57 & T $\times$ P: $9.45^{d}$ \\
& 2 & 1.90 & 1.81 & T: .21 \\
Arousal & 3 & 2.23 & 1.77 & P: $7.48^{d}$ \\
& 1 & 1.45 & 1.83 & T $\times$ P: $12.08^{d}$ \\
Control & 2 & 2.98 & 3.42 & T: 1.05 \\
& 3 & 3.00 & 3.26 & P: $3.96^{c}$ \\
& 1 & 3.66 & 3.30 & T $\times$ P: $7.02^{d}$ \\
\hline
\end{tabular}

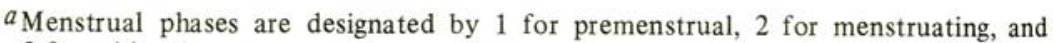
3 for midcycle.

$b_{F}$ tests for type of questionnaire $\mathrm{T}$ have 1 and 25 degrees of freedom; those for phase $P$ and interaction $P \times T$ have 2 and 50 degrees of freedom.

$c$ Significant at $p<.05$.

$d_{\text {Significant at } p<.01 \text {. }}$

${ }^{e}$ Significant at $p<.10$.

as many menstrual cycles as a subject had during the study (two or three). It was assumed that such an MDQ would capture cyclical variations that may not occur in every menstrual cycle and yet may be the ones that women remember. This analysis, however, yielded only one additional significant main phase effect on the water retention factor $(F=3.48, d f=2,88 ; p<.05)$ and a significant interaction effect on the same factor $(F=3.19, d f=2,88 ; p<.05)$. In addition, the interaction effect on the pain factor also reached significance $(F=4.78, d f=2,88$; $p<.05)$. On both factors the pill women had lower scores than nonpill women, with the largest difference in the menstrual phase. 
Table IV. Means on Remembered and Actual Last Cycle MDQs by Condition and $F$ Values for Women Taking Oral Contraceptives

\begin{tabular}{lcccl}
\hline MDQ factors & $\begin{array}{c}\text { Menstrual } \\
\text { phase }^{a}\end{array}$ & Remembered (20) & Actual (20) & \multicolumn{1}{c}{$F$ Values $b$} \\
\hline Pain & 1 & 2.07 & 1.48 & $\mathrm{~T}: 11.50^{c}$ \\
& 2 & 1.96 & 1.66 & $\mathrm{P}: 14.07 c$ \\
Concentration & 3 & 1.52 & 1.40 & $\mathrm{~T} \times \mathrm{P}: 3.57^{d}$ \\
& 1 & 1.36 & 1.49 & $\mathrm{~T}: 5.85^{d}$ \\
Behavioral & 2 & 1.29 & 1.40 & $\mathrm{P}: 1.66$ \\
change & 3 & 1.29 & 1.53 & $\mathrm{~T} \times \mathrm{P}: .74$ \\
& 1 & 1.80 & 1.81 & $\mathrm{~T}: .00$ \\
Autonomic & 3 & 1.88 & 1.78 & $\mathrm{P}: 2.54 e$ \\
reaction & 1 & 1.62 & 1.72 & $\mathrm{~T} \times \mathrm{P}: .52$ \\
& 2 & 1.17 & 1.08 & $\mathrm{~T}: 2.03$ \\
Water & 3 & 1.21 & 1.06 & $\mathrm{P}: .52$ \\
retention & 1 & 1.08 & 1.09 & $\mathrm{~T} \times \mathrm{P}: 1.55$ \\
& 2 & 2.18 & 1.47 & $\mathrm{~T}: 22.42 c$ \\
Negative & 3 & 1.99 & 1.49 & $\mathrm{P}: 7.05 c$ \\
affect & 1 & 1.50 & 1.39 & $\mathrm{~T} \times \mathrm{P}: 6.92 c$ \\
& 2 & 2.09 & 1.78 & $\mathrm{~T}: 3.54 e$ \\
Arousal & 3 & 1.94 & 1.62 & $\mathrm{P}: 1.35$ \\
& 1 & 1.73 & 1.84 & $\mathrm{~T} \times \mathrm{P}: 2.30$ \\
Control & 2 & 3.10 & 3.13 & $\mathrm{~T}: .23$ \\
& 3 & 3.19 & 3.31 & $\mathrm{P}: 4.05^{d}$ \\
& 1 & 3.56 & 3.23 & $\mathrm{~T} \times \mathrm{P}: 2.74 e$ \\
\hline
\end{tabular}

${ }^{a}$ Menstrual phases are designated by 1 for premenstrual, 2 for menstruating, and 3 for midcycle.

$b F$ tests for type of questionnaire $\mathrm{T}$ have 1 and 19 degrees of freedom; those for phase $\mathrm{P}$ and interaction $\mathrm{P} \times \mathrm{T}$ have 2 and 38 degrees of freedom.

${ }^{c}$ Significant at $p<.01$.

$d_{\text {Significant at } p<.05 \text {. }}$.

eSignificant at $p<.10$.

A $3 \times 2$ factorial analysis of variance for repeated measures (with remembered versus actual last MDQs and premenstrual, menstrual, and midcycle phases of the menstrual cycle as the two independent variables) was performed separately for the two groups of women. Table III shows the means on remembered and actual last cycle MDQs across the different phases of the menstrual cycle for nonpill women. $F$ values for main effects due to the different types of MDQs (T), main effects due to menstrual phase $(\mathrm{P})$, and interaction effects $(\mathrm{T} \times$ P) are also indicated.

As can be seen in Table III, main effects due to menstrual phase were significant on all factors except concentration and control. These effects reflect 
mostly the cyclical variations on the remembered MDQ. However, the two types of MDQs appeared to be significantly different on factors of pain, concentration, autonomic reaction, and water retention, as reflected by significant main effects due to questionnaire type. The difference between the two MDQs is also reflected in the significant interaction effects $(\mathrm{T} \times \mathrm{P})$ on all factors except concentration and arousal; highest scores were obtained on the remembered MDQ for the menstrual phase of the cycle.

Table IV shows equivalent results for women taking oral contraceptives. As can be seen, the two types of MDQs were significantly different on factors of pain, concentration, and water retention. Significant main effects due to menstrual cycle occurred only on factors of pain, water retention, and arousal. The significant interaction effects were obtained on factors of pain and autonomic reaction. In both factors, highest scores occurred on the remembered MDQ in the premenstrual phase of the cycle.

\section{DISCUSSION}

By having male and female subjects fill out a daily MDQ, over an extended period of time, under the guise of a study of biological rhythms common to both men and women, it was hoped to obtain self-report measures less biased by cultural expectations about the menstrual cycle. The present study suggests that questionnaires that make women aware that the menstrual cycle is being studied may exaggerate cyclical variations of moods and behaviors. Examination of Tables I and II indicates that only the remembered MDQ yielded cyclical variations related to the menstrual cycle similar to those reported by Moos (1969a,b,c) on all factors, with the exception that concentration did not quite reach significant cyclical variation whereas arousal did. However, the actual last MDQ yielded a cyclical variation related to the menstrual cycle only on the factor of pain.

The lack of menstrual cycle phase effects on the other factors was surprising, especially in view of the fact that such effects showed up on the remembered MDQ that covered the same menstrual cycle. Since even the composite MDQ added only one phase effect, it is possible that a remembered MDQ is affected by either memory of symptomatology that occurs relatively infrequently or by broad cultural expectations pertaining to the menstrual cycle. The significant interactions between phase and questionnaire type (remembered vs. actual), as reflected in Tables III and IV, indicate that the two types of questionnaires may indeed not be equivalent.

In general, the largest cyclical variations occurred on the remembered MDQ. Women not taking oral contraceptives usually reported the highest symptomatology during menstruation. An interesting exception occurred on the 
arousal factor for both nonpill and pill women. On the remembered MDQ both groups obtained highest scores at midcycle; on the other hand, neither group obtained highest scores at midcycle on the actual last MDQ. Perhaps this is not surprising when one remembers that the arousal factor is hypothesized to measure positive affect. It is possible that these results reflect the cultural expectations about positive moods at midcycle, as summarized by Parlee (1973).

With respect to the differences between nonpill and pill women, on the remembered MDQ, present results did not generally replicate those of Moos (1969a,b,c), who found nonpill women reporting higher symptomatology both menstrually and premenstrually compared to pill women. It is possible that individual variability and the relatively small sample of women masked some of the differences. However, changes in hormonal concentrations in oral contraceptives over the last few years could also be responsible for the present results.

The type of analyses performed on the present data indicates possible memory and/or cultural effects on the remembered MDQ. However, a more appropriate analysis might look for individual shifts in moods and behaviors across the menstrual cycle without the present restrictive time definitions of menstrual phases. Perhaps some of the factors have short-term effects compared to others and perhaps these vary for different women. Therefore, the present results do not negate the experiences of individual women; rather they point out that retrospective questionnaires, which make the menstrual cycle a salient part of the study, may exaggerate cyclical variability of moods and behaviors.

\section{REFERENCES}

Edwards, A. L. Experimental design in psychological research. New York: Holt, Rinehart \& Winston, 1950.

Englander-Golden, P., Willis, K. A., \& Dienstbier, R. A. Intellectual performance as a function of repression and menstrual cycle. Presented at the American Psychological Association 84th Annual Convention, Washington, D.C., Sept. 3-7, 1976.

Englander-Golden, P., Willis, K. A., \& Dienstbier, R. A. Stability of perceived tension as a function of the menstrual cycle. Journal of Human Stress, 1977,3, 14-21.

Gough, H. G. Personality factors related to reported severity of menstrual distress. Journal of Abnormal Psychology, 1975, 84, 59-65.

Klaiber, E. L., Kobayashi, Y., Braverman, D. M., \& Hall, F. Plasma Monamine Exidase Activity and Sex Hormone Concentration in Human Blood Plasma. Journal of Reproduction and Fertility, 1972, 29, 447-450.

Moos, R. H. The development of a menstrual distress questionnaire. Psychosomatic Medicine, 1968, 30, 853-867.

Moos, R. H. Typology of menstrual cycle symptoms. American Journal of Obstetrics and Gynecology, 1969, /03, 390-402. (a)

Moos, R. H. Assessment of psychological concomitants of oral contraceptives. In W. Salhanic, D. Kinross, \& R. VanDeweble (Eds.), Metabolic effects of gonadal hormones and con traceptive agents. New York: Plenum Press, 1969. (b) 
Moos, R. H. Menstrual Distress Questionnaire Preliminary Manual. Stanford University, Department of Psychiatry, 1969. (c)

Parlee, M. B. The premenstrual syndrome. Psychological Bulletin, 1973, 80, 454-465.

Rodin, J. Menstruation, reattribution, and competence. Journal of Personality and Social Psychology, 1976, 33, 345-353.

Silbergeld, S., Brast, N., \& Noble, E. P. The menstrual cycle: A doubleblind study of symptoms, mood and behavior, and biochemical variables using Enovid and placebo. Psychosomatic Medicine, 1971,33, 411-428.

Sommer, B. Menstrual cycle changes and intellectual performance. Psychosomatic Medicine, 1972,34, 263-269.

Williams, R. H. Textbook of endocrinology. Philadelphia: W. B. Saunders, 1974. 